\title{
Developing tools for assessing intention to receive the COVID-19 vaccine based on the health belief model
}

azam maleki ( $\square$ malekia@zums.ac.ir )

Research article

Keywords: Covid-19 vaccine, psychometrics properties, health belief model

Posted Date: October 28th, 2021

DOI: https://doi.org/10.21203/rs.3.rs-1027319/v1

License: (c) (i) This work is licensed under a Creative Commons Attribution 4.0 International License.

Read Full License 


\section{Abstract \\ Background}

The study was aimed to evaluate the psychometric properties of intention to receive the COVID-19 vaccine using a health belief model.

\section{Method}

The study was a test and tools design study that was conducted in the period from February to March 2020. Questionnaire items were designed using text review. The sampling method was multi-stage. Data were analyzed using descriptive statistics, confirmatory and exploratory factor analysis at $95 \%$ confidence level using SPSS software version 16.

\section{Results}

The questionnaire had an appropriate content validity and internal consistency. The 5-factor was extracted and the conceptual model had good fit indices. Cronbach Alpha coefficient was 0.82 and the intra-class correlation coefficient (ICC) was 0.9 .

\section{Conclusion}

It can be concluded that the designed instrument had good validity and reliability indicators. The constructs of the health belief model well explain the determinants of the intention to receive the Covid-19 vaccine at the individual level.

\section{Background}

Since December 2019, COVID-19 has been the cause of acute respiratory syndrome in Wuhan, China. However, due to the high spread of the virus, it has almost changed from an epidemic in China to a pandemic, and most countries in the world, including IRAN, are affected by Covid-19 disease (1). Based on what is currently known about SARS-CoV-2, the spread of the disease from a person infected with the virus often occurs in close contact. There is currently no drug available for COVID-19 (2). The only definitive way to reduce the prevalence of this disease is to create herd immunity. Herd immunity is usually possible through direct infection or immunization of at least $65 \%$ of the population using universal vaccination.

Preliminary evidence of direct immunity to the virus indicates that the duration of immunity is limited and, in some cases, reported to be unknown, and the financial, human, medical, and long-term complications of the disease are so high that it completely ignores this policy. The second way, vaccination, in addition 
to financial and human resources, requires the cooperation of different groups, and different aspects must be considered in its planning. Negative attitudes toward vaccines are one of the major concerns for achieving collective safety $(3,4)$. The second way, vaccination, in addition to financial and human resources, requires the cooperation of different groups, and different aspects must be considered in its planning. Negative attitudes toward vaccines are one of the major concerns for achieving herd immunity $(3,4)$. One of the first steps in assessing behavioral intent and determinants of mass acceptance of Covid-19 vaccination. According to a survey of the general population of 19 countries, the vaccine acceptance rate is $71.5 \%$. The highest acceptance rate in China was approximately $90 \%$ and the lowest in Russia was $55 \%$ (5). One of the important measures in increasing the acceptance of vaccination is the use of health education models (6). One of the effective models in this field is the model of health belief model (7). This model includes behavioral intent and elements of perceived sensitivity and intensity, perceived benefits and barriers, guided action, and perceived self-efficacy (7). Perceived susceptibility during the Covid-19 epidemic is when people consider themselves at risk for Covid-19 and perceived severity means that the disease has serious and potential consequences for them. If the perceived benefits outweigh the barriers to vaccination, people will believe that following preventative measures such as getting the Covid-19 vaccine will have a positive effect and reduce symptoms. Therefore, they will be more likely to be able to get the Covid-19 vaccine (self-efficacy). A structure called the action guide also expresses stimuli that affect the person from inside or outside and cause the person to adopt desirable preventive behaviors according to the levels of perceived sensitivity, perceived severity, perceived barriers, and perceived benefits. These variables are thought to be influenced by demographic variables such as race, age, and socioeconomic status (8). In this regard, Shmueli et al. 2021 showed that the intention to receive the Covid-19 vaccine had a significant relationship with perceived benefits, perceived severity, and cue to action (9). In another study in Greece, the intention to accept a vaccine with perceived benefits had the greatest effect and the perceived sensitivity had the least effect on receiving the vaccine (10). In Bangladesh, perceived benefits, perceived severity, and perceived barriers were associated with reduced hesitancy about vaccine acceptance in the general population (11). Based on the published findings, the application of behavioral change models in accepting the Covid- 19 vaccine has been tested using a health belief model in the general population. However, in most of these studies, the questionnaires were researcher-made and the steps of psychometric properties of the instrument were not fully investigated. To achieve valid results, access to a valid questionnaire is essential. The present study was conducted to design and evaluate the psychometric properties of intention to receive the COVID-19 -9 vaccine using a health belief model in the research community of health workers in Iran

\section{Method}

\section{Study design \& Setting}

The present study was a test and tools design study that conducted in the period from February to March 2020 after approval and obtaining the code of ethics from the Medical Ethics Committee of Zanajn University of Medical Sciences with the aim of designing and psychometric properties of intention to 
receive Covid-19 vaccine questionnaire based on HBM model structures in health staff performed. The study population included health workers working in 9 provinces of Iran

\section{Psychometric properties}

\section{Items design}

Questionnaire items were designed using text review. After the initial screening, several questions measuring the common goal were combined or omitted with the opinion of the research team and consultation with experts. Therefore, the questions of the questionnaire were reduced from 35 questions to 20 questions.

\section{Face validity}

To evaluate the qualitative face validity, the questions were checked with 10 participants in terms of difficulty level, appropriateness, or ambiguity. For quantitative face validity, first, for each of the questionnaire expressions, the 5-point Likert scale is quite important (score 5) to not at all important (score 1). Then, 15 participants were asked to review and grade each of the phrases based on their experiences. Questions with an item impact index greater than 1.5 were identified and retained as appropriate for subsequent analysis.

\section{Content validity}

The content of the questionnaire was validated both quantitatively and qualitatively. To evaluate the validity of qualitative content, a questionnaire was given to 10 experts. Experts were asked to submit written comments on the content in terms of grammar, use of appropriate phrases in the items. After receiving qualitative feedback from experts and correcting comments, quantitative review of content validity as a complementary method in content validity to ensure that the most important and correct content is selected and tool questions are best designed to measure content designed. Quantitative content validity was assessed by calculating the Content Validity Ratio (CVR) and the Content Validity Index (CVI) for items. The maximum acceptable value for the content validity ratio based on the Lawshe table is 0.62 (12) and a CVI score higher than 0.79 was considered appropriate.

\section{Construct validity}

To evaluate the validity of the structure and determine the dimensions of the questionnaire, exploratory factor analysis was performed using SPSS software version 16. Principal Component Analysis was performed for hidden variables with varimax rotation and eigenvalue above 1 and cut-off point of 0.5 . The factor load of each question in the factor matrix and the rotated matrix was considered at least 0.3. The sample size at this stage was 1227 people. The KMO test and the Bartlett test (BT) were used to 
assess the suitability of the sample for factor analysis and the Scree plot to determine the number of constituents of the questionnaire.

Confirmatory factor analysis was used to confirm the number of factors and their relationship with items. For this purpose, the factors extracted by exploratory factor analysis were evaluated using confirmatory factor analysis (CFA) and goodness-of-fit index on 400 samples. The goodness-of-fit index in the present study included Confirmatory Fit Index (CFI), Good Fit Index (GFI), and Incremental Fit Index (IFI) that the acceptable level of these indices was considered more than 0.9. Also, the Adjusted Goodness of Fit Index (AGF) with an acceptable level of more than 0.80 , the root mean square error index of estimation (RMSEA) with an acceptable level of less than 0.08 , and normal or relative chi-square with a level of less than 3 was considered acceptable (13).

The sample size of 5-10 per expression is usually considered sufficient for factor analysis in terms of the number of participants(14). In this study, due to access to sufficient sample size, exploratory factor analysis was performed on 1227 people and confirmatory factor analysis was performed on 400 people. Inclusion criteria included willingness to participate in the study and having at least three months of work experience in selected sampling centers. The exclusion criteria included unwillingness to continue cooperation and incomplete questionnaires. The sampling method was multi-stage, in the first stage, each province was considered as a cluster. In each cluster, individuals were randomly selected according to the job and then according to the calculated ratio of sample size in each category. In the center of the province, a Covid-19 center hospital along with another hospital, preferably a general hospital, and 5 comprehensive urban health centers, and 5 comprehensive rural health centers were randomly selected and sampled with the specified number of quotas.

\section{Reliability \& Stability of questionnaire}

In this study, to determine the reliability, Cronbach's alpha coefficient and also the intra-class correlation coefficient was used by test re-testing 15 eligible individuals in two stages with an interval of two weeks completed the questionnaire. Then the intragroup correlation or ICC coefficient was calculated. In designing and evaluating the psychometrics of this instrument, the steps and analyses proposed by the COSMIN checklist were considered (15).

In the present study, questionnaires were collected by trained individuals following scientific and accurate instructions through a face-to-face consultation.

Data were collected using a demographic questionnaire and the intention to receive vaccines and health belief model constructs. The demographic questionnaire included age, gender, and place of work.

Intention to receive the vaccine was assessed with a question in three grades: "Acceptance of the vaccine, resistance to receiving the vaccine and hesitancy about receiving the vaccine."

Health belief model constructs include perceived sensitivity (3 questions), perceived severity ( 2 questions), perceived benefits (3 questions), perceived barriers (5 questions), cue to action (4 questions), 
and perceived self-efficacy (2 Questions). The questions were graded on 5 Likert scales. The questions of the perceived barrier domains were inversely and the rest of the domains were directly scored. Scores ranged from 16 to 80 .

\section{Data analysis}

Data were analyzed using SPSS software version 16. Descriptive statistics indicators were used to describe the data. Confirmatory and exploratory factor analysis was used for construct validity.

\section{Results}

\section{Baseline data}

The results showed that the highest percentage of participants in the study were in the age group of 26 to 35 years (39.8\%), female gender (57.1\%), and employed in the hospital (52.5\%) (Table 1).

\section{Psychometric properties}

\section{Face validity}

In qualitative face validity, all questions fit the objectives of the research. For people with a diploma or higher, it was easy and the questions were not ambiguous.

The quantitative face validity results in the present study showed that all items had an impact score greater than 1.5 and they were considered important by the target group.

\section{Content validity}

The results showed that since the CVR numerical value of all questions was greater than the number of the Lawshe table (0.62), the content validity of all questions was confirmed. Thus, the existence of all questions with an acceptable statistical significance level in this tool was essential. Also, all items had a $\mathrm{CVI}$ score higher than $\mathbf{0 . 7 9}$, so they were considered appropriate. Since the impact score, content validity ratio, and content validity index of all items were appropriate, the research team did not remove any items from the tool.

\section{Construct validity}

In the study of construct validity and determining the dimensions of the questionnaire, the results of exploratory factor analysis showed that the KMO and BT tests were $0.875,7767.480$, and $p=0.001$, respectively. The $\mathrm{KMO}$ sampling index in this model was above 0.7 , which indicates that the data are sufficient for analysis, and the BT test was significant, indicating that there is sufficient correlation between the variables to analyze the factor. 
The Scree plot confirms the existence of five factors visually. This graph shows that the eigenvalues of the 5 factors were higher than one, and this confirms that the 5 extracted factors are appropriate (Figure 1). The variables entered in the analysis are loaded on these 5 factors, which together explain $63.93 \%$ of the variance.

The first factor consisted of 4 questions, the second factor consisted of 5 questions, the third factor consisted of 3 questions, the fourth factor consisted of 5 questions, and the fifth factor consisted of 2 questions. Each factor was named based on the extracted content as guided action, perceived sensitivity and intensity, perceived benefits, perceived barriers, and perceived self-efficacy, respectively. The Health Belief Model Structures Questionnaire was approved with 19 questions (Table 2), which by adding a behavioral question, the final questionnaire became a total of 20 questions.

The results of confirmatory factor analysis showed that the GFI were at an acceptable level $(\mathrm{X} 2 / \mathrm{df}=$ 2.782; $\mathrm{df}=134 ; \mathrm{p}<0.001 ; \mathrm{CFI}=0.902 ; \mathrm{GFI}=0.914 ; \mathrm{IFI}=0.904 ; \mathrm{AGFI}=0.877 \mathrm{RMSEA}=0.067)$. The schematic view of the model with factor loads is shown in the figure2.

\section{Reliability \& Stability of questionnaire}

In this study, the internal consistency coefficient of the instrument was determined by calculating Cronbach's alpha coefficient. For this purpose, 30 questionnaires were distributed among the research units. Cronbach's alpha coefficient of the whole tool was calculated to be 0.82 . Cronbach's alpha coefficient of domains and item by item is listed in Table $\mathbf{3}$.

To determine the stability of the questionnaire in the reproducibility dimension, the interclass correlation coefficient (ICC) was calculated. In this part of the study, 20 research units completed the final questionnaire twice in two weeks. The results of the intra-class correlation coefficient of all items were 0.91 .

In addition, the relationship between each item and its structure was examined using the Spearman correlation coefficient. All items in each structure had the most relationship with their structure.

\section{Discussion}

The results of exploratory factor analysis showed that a 5 -factor structure (perceived sensitivity and severity, perceived benefits, perceived barriers, guidance for action, and perceived self-efficacy) was used to predict the intention to receive the Covid-19 vaccine in this sample of health workers following structures of the health belief model. The findings of the study showed that based on the method of maximum likelihood and varimax rotation, 5 known factors explain 63.93 of the variance of behavior. Accordingly, this tool seems comprehensive in terms of explaining the intention to receive Covid-19 vaccination by health workers. Also, in this study, the GFI obtained from the confirmatory factor analysis was at an acceptable level to confirm the model. 
The high correlation of each item indicates that the item was effective and sufficient to measure the behavior and confirms the independence of the structures to measure the intended concept. The overall Cronbach's alpha coefficients and all components of scales except perceived self-efficacy were high and appropriate range. Based on the literature review, the present questionnaire is the first standard questionnaire designed to determine the intention to receive Covid-19 vaccination based on the structures of the health belief model in the population of health workers. However, in some studies, which have been limited to determining the intention to receive the Covid-19 vaccine in health workers, it is not based on the model, or all the design steps and psychometric properties of the instruments have not been studied $(16,17)$.

Limited studies have been performed to evaluate the intention to receive the Covid-19 vaccine in the general population. In this regard, Shmueli et al. in 2021 examined the intention to receive the Covid-19 vaccine based on the structures of the health belief model in the general population with 11 questions in 5 factors. Questionnaire constructs related to influenza vaccination used for Covid-19. In Shmueli's study, the questionnaire had good reliability(9) which was consistent with the results of the present study. In another study, Bellal Hossain et al. in Bangladesh in 2021 examined the intention to receive the Covid-19 vaccine with 16 questions in 5 structures of the health belief model. The steps of questionnaire design and psychometrics were not mentioned in the article. Also, only two of the structures had good reliability (11). In the study of Wong et al. in Hong Kong, a behavioral intention questionnaire of cancer patients was used. Since the aim of the study was to accept the Covid-19 vaccine, the validity and reliability of the questionnaire were not re-evaluated (8). The use of HBM constructs as an important predictor in receiving other vaccines, including influenza vaccine (18), papillomavirus vaccine (19) had a good performance, which is in line with the results of the present study and shows the structure of Health belief models in getting Covid-19 vaccine are just as effective as other vaccines.

The main goal of public health is to protect and improve people's health and changing people's behavior is a key element to achieve this goal (20). The role of individuals' beliefs and attitudes in social cognitive theories has also been emphasized (21). Intention to do behavior is one of the important predictors of real behavior (22). However, according to studies, although a person may intend to behave in a certain way, the intention does not always turn into actual behavior $(23,24)$. The vaccination program is currently considered to be the most effective strategy against the Covid-19 outbreak (25) and identifying the attitudes and beliefs of individuals in this regard, planning and designing interventions to reduce the nonacceptance or receipt of vaccines is one of the most important public health issues (26). The implications of the health belief model in this study include perceived sensitivity and severity (a person's perception of the risk of a disease and a person's perception of the consequences of a disease), also known as a perceived threat, perceived benefits (as a person's awareness regarding the benefits of a recommended health protection behavior), perceived barriers (understanding the factors that prevent or make it difficult to perform such a health protection behavior), perceived self-efficacy (belief in one's own ability to perform the recommended behavior), and Cues to action (21). Awareness of these attitudes and beliefs under these headings leads to the design of realistic interventions that provide an optimal solution. 
One of the strengths of studying is the high sample size with equal sex categories and high diversity of job positions, the second, the use of exploratory and confirmatory factor analysis methods for construct validity. The preliminary stage of psychometrics properties of the designed questionnaire was done. The items of the questionnaire were generated by a review of previous studies. Therefore, these limitations should be considered when interpreting these findings.

\section{Conclusion}

It can be concluded that the instrument designed in the preliminary stage of psychometrics properties to determine the intention to receive the Covid-19 vaccine in the research community of health workers had good validity and reliability indicators. Also, the constructs of the health belief model well explain the determinants of the intention to receive the Covid-19 vaccine at the individual level.

\section{Abbreviations}

HBM

Health Belief Model

Covid-19

Coronavirus Disease 2019

\section{Declarations}

Ethical Approval: This article was a part of a national project and approved by the Ethics Committee of the Vice Chancellor for Research of Zanjan University of Medical Sciences, Iran, with the approval number IR.ZUMS.REC.1399.455. All procedures of the study were following the protocol of the regional ethical research committee and with the declaration of Helsinki 1964. After informing the study's purposes, written consent was obtained from all participants. They were informed that their participation was voluntary, confidential, and anonymous, and was apprised of their right to withdraw from the research at any time.

\section{Availability of data and materials}

The data sets used and analyzed during the current study are available from the corresponding author on reasonable request

\section{Competing interests}

No potential conflict of interest relevant to this article was reported

\section{Funding Sources.}

This article was part of a national project and funded by UNICEF and it was approved by the Research Deputy of Zanjan University of Medical Sciences, Iran, with the approval number (The code " A-12-179- 
47"). UNICEF contributed financially and Zanjan University of Medical Sciences has also been involved in the implementation of the project and the supply of human resources for the implementation of the project.

\section{Acknowledgements}

We would like to thank Zanjan University's vice-chancellor of research and technology for their technical support to carry out the study (The code " A-12-179-47")."). We would like to thank the staff of the Infectious Disease Management Center of the Ministry of Health of Iran, and 9 provinces included the university of Iran, Hazmargan, Qom, Rafsanjan, Mazandaran, Khorasan Razavi, Ahvaz, Urmia, Ilam for their collaboration, and participation.

Consent for publication: Not Applicable

\section{Authorship}

This study was one part of the national project of Alireza Shogli. He is Principal Investigator and Grant Recipient. The conception, design of the study, and data collection process were undertaken by Khadija Hajimiri, Zarrintag Hoseinzade and Azam Maleki. Koorosh Kamali, Mohammad Mehdi Gouya , Seyed Mohsen Zahraei , Soodabeh Hoveidamanesh, and Soodabeh Hoveidamanesh were contributed to the design of the study and reporting of the results. Soraya Mohamadi, Zohreh Bigdeli, Mahya Farsadegi, Zahra Heidari, and Tahereh mohamadi were were contributed to data collection, data quality control, and data entry. Analysis, interpretation, and reporting were supervised by Azam Maleki and Koorosh Kamali . All authors contributed to the drafting and revising of the article and are in agreement with the final version of the manuscript to be submitted to the journal

\section{References}

1. Organization WH. (2020).Rolling updates on coronavirus disease (COVID-19). Geneva: World Health Organization.

2. Roser M, Ritchie H, Ortiz-Ospina E, Hasell J.(2020). Coronavirus disease (COVID-19)-Statistics and research. Our World in data.4.

3. Haynes BF, Corey L, Fernandes P, Gilbert PB, Hotez PJ, Rao S, et al. (2020). Prospects for a safe COVID-19 vaccine. Science translational medicine. 12(568).

4. Polack FP, Thomas SJ, Kitchin N, Absalon J, Gurtman A, Lockhart S, et al. (2020). Safety and efficacy of the BNT162b2 mRNA Covid-19 vaccine. New England Journal of Medicine. 383(27):2603-15.

5. Lazarus JV, Ratzan SC, Palayew A, Gostin LO, Larson HJ, Rabin K, et al.( 2021). A global survey of potential acceptance of a COVID-19 vaccine. Nature medicine. 27(2):225-8. 
6. D'Souza C, Zyngier S, Robinson P, Schlotterlein M, Sullivan-Mort G. (2011). Health belief model: Evaluating marketing promotion in a public vaccination program. Journal of Nonprofit \& Public Sector Marketing. 23(2):134-57.

7. Champion VL, Skinner CS.(2008). The health belief model. Health behavior and health education: Theory, research, and practice.4:45-65.

8. Wong LP, Alias H, Wong P-F, Lee HY, AbuBakar S.(2020). The use of the health belief model to assess predictors of intent to receive the COVID-19 vaccine and willingness to pay. Human vaccines \& immunotherapeutics. 16(9):2204-14.

9. Shmueli L.(2021). Predicting intention to receive COVID-19 vaccine among the general population using the health belief model and the theory of planned behavior model. BMC Public Health.21(1):1-13.

10. Zampetakis LA, Melas C. (2021). The health belief model predicts vaccination intentions against COVID-19: A survey experiment approach. Applied Psychology: Health and Well-Being.

11. Hossain MB, Alam MZ, Islam MS, Sultan S, Faysal MM, Rima S, et al.(2021). Health Belief, Planned Behavior, or Psychological Antecedents: What predicts COVID-19 Vaccine Hesitancy better among the Bangladeshi Adults? medRxiv.

12. Lawshe CH.(1975). A quantitative approach to content validity. Personnel psychology.28(4):56375 .

13. Pahlevan Sharif S, Sharif Nia H. (2018). Structural equation modeling with AMOS. Tehran: Artin Teb.

14. Munro BH. (2013). Statistical methods for health care research: lippincott williams \& wilkins.

15. Terwee CB, Mokkink LB, Knol DL, Ostelo RW, Bouter LM, de Vet HC. (2012). Rating the methodological quality in systematic reviews of studies on measurement properties: a scoring system for the COSMIN checklist. Quality of life research.21(4):651-7.

16. Mohamed-Hussein AA, Makhlouf H, Abd El Aal H, Kholief K, Saad MM, Abdellal DA.( 2021). A national survey of potential acceptance of COVID-19 vaccines in healthcare workers in Egypt. medRxiv.

17. Nzaji MK, Ngombe LK, Mwamba GN, Ndala DBB, Miema JM, Lungoyo CL, et al. (2020).Acceptability of Vaccination Against COVID-19 Among Healthcare Workers in the Democratic Republic of the Congo. Pragmatic and observational research.11:103.

18. Shahrabani S, Benzion U. (2010). Workplace vaccination and other factors impacting influenza vaccination decision among employees in Israel. International journal of environmental research and public health.7(3):853-69. 
19. Guvenc G, Seven M, Akyuz A. (2016). Health belief model scale for human papilloma virus and its vaccination: adaptation and psychometric testing. Journal of pediatric and adolescent gynecology.29(3):252-8.

20. Maurer FA, Smith CM. (2012). Community/public health nursing practice: Health for families and populations: Elsevier Health Sciences.

21. Glanz K, Rimer BK, Viswanath K. (2008). Health behavior and health education: theory, research, and practice: John Wiley \& Sons.

22. Fall E, Izaute M, Chakroun-Baggioni N. (2018). How can the health belief model and selfdetermination theory predict both influenza vaccination and vaccination intention? A longitudinal study among university students. Psychology \& health. 33(6):746-64.

23. Gollwitzer PM, Sheeran P. (2006) Implementation intentions and goal achievement: A metaanalysis of effects and processes. Advances in experimental social psychology. 38:69-119.

24. Webb TL, Sheeran P.(2007). How do implementation intentions promote goal attainment? A test of component processes. Journal of Experimental Social Psychology. 43(2):295-302.

25. DeRoo SS, Pudalov NJ, Fu LY. .(2020) Planning for a COVID-19 vaccination program. Jama. 323(24):2458-9.

26. Larson HJ, Jarrett C, Schulz WS, Chaudhuri M, Zhou Y, Dube E, et al.(2015). Measuring vaccine hesitancy: the development of a survey tool. Vaccine.33(34):4165-75.

\section{Tables}

Table 1 Frequency distribution and percentage of demographic characteristics of participants 


\begin{tabular}{|c|c|c|c|c|c|c|c|}
\hline & & Frequency & Percent & & & Frequency & Percent \\
\hline \multirow{5}{*}{$\begin{array}{l}\text { Age } \\
\text { groups } \\
\text { (year) }\end{array}$} & $\begin{array}{l}19- \\
25\end{array}$ & 87 & 7.1 & \multirow[t]{2}{*}{ Sex } & Female & 700 & 57.1 \\
\hline & $\begin{array}{l}26- \\
35\end{array}$ & 488 & 39.8 & & Male & 526 & 42.9 \\
\hline & $\begin{array}{l}36- \\
45\end{array}$ & 441 & 36.0 & \multirow[t]{3}{*}{$\begin{array}{l}\text { Work } \\
\text { place }\end{array}$} & Hospital & 644 & 52.5 \\
\hline & $\begin{array}{l}46- \\
55\end{array}$ & 195 & 15.9 & & $\begin{array}{l}\text { Community } \\
\text { health center }\end{array}$ & 309 & 25.2 \\
\hline & $>55$ & 14 & 1.1 & & $\begin{array}{l}\text { Local Health } \\
\text { center }\end{array}$ & 274 & 22.3 \\
\hline
\end{tabular}

Table 2: Factor load values of 5 factors extracted from the Questionnaire based on the structures of the health belief model using the Varimax rotation

\begin{tabular}{|c|c|c|c|c|c|c|}
\hline \multicolumn{7}{|c|}{ Rotated Component Matrix ${ }^{\mathrm{a}}$} \\
\hline & & \multicolumn{5}{|c|}{ Component } \\
\hline & & 1 & 2 & 3 & 4 & 5 \\
\hline \multirow[t]{4}{*}{ Cue to action } & S1 & & .786 & & & \\
\hline & S2 & & .766 & & & \\
\hline & S3 & & .712 & & & \\
\hline & S4 & & .631 & & & \\
\hline \multirow[t]{5}{*}{ Perceived susceptibility \& severity } & S5 & & & .411 & & \\
\hline & S6 & & & .733 & & \\
\hline & S7 & & & .538 & & \\
\hline & S8 & & & .829 & & \\
\hline & S9 & & & .765 & & \\
\hline \multirow[t]{3}{*}{ Perceived benefits } & $\mathrm{S} 10$ & & & & .694 & \\
\hline & $\mathrm{S} 11$ & & & & .731 & \\
\hline & $\mathrm{S} 12$ & & & & .651 & \\
\hline \multirow[t]{5}{*}{ Perceived barriers } & S13 & .741 & & & & \\
\hline & $\mathrm{S} 14$ & .786 & & & & \\
\hline & S15 & .820 & & & & \\
\hline & S16 & .812 & & & & \\
\hline & $\mathrm{S} 17$ & .767 & & & & \\
\hline \multirow[t]{2}{*}{ Self-efficacy } & $\mathrm{S} 18$ & & & & & .855 \\
\hline & S19 & & & & & .670 \\
\hline
\end{tabular}


Table 3: Cronbach's alpha coefficient of extracted factors and items of Intention to receive Covid-19 vaccine questionnaire based on health belief model constructs

\begin{tabular}{|c|c|c|c|c|}
\hline \multicolumn{2}{|r|}{ Items } & \multirow{5}{*}{$\begin{array}{r}\text { Health Belief } \\
\text { Model Constructs } \\
\text { Cue to action }\end{array}$} & \multicolumn{2}{|c|}{$\begin{array}{l}\text { Cronbach's } \\
\text { Alpha }\end{array}$} \\
\hline S1 & $\begin{array}{r}\text { I intend to receive the COVID-19 vaccine, if it recommends by a } \\
\text { reliable professional expert. }\end{array}$ & & 0.78 & .815 \\
\hline S2 & $\begin{array}{l}\text { I intend to receive the COVID-19 vaccine if it recommends by } \\
\text { the official local authorities (exp. ministry of health) }\end{array}$ & & & .819 \\
\hline S3 & $\begin{array}{r}\text { I intend to receive the COVID-19 vaccine if it recommends by } \\
\text { the official international authorities (exp. WHO) }\end{array}$ & & & .815 \\
\hline S4 & $\begin{array}{l}\text { I plan to receive the COVID-19 vaccine after reporting its side } \\
\text { effects by the national/ international organization. }\end{array}$ & & & .818 \\
\hline S5 & I am worry to become infected by the COVID-19 very soon. & Perceived & 0.76 & .817 \\
\hline S6 & $\begin{array}{r}\text { Due to my job situation, I am more likely to become infected by } \\
\text { Covid-19 }\end{array}$ & rity & & .822 \\
\hline S7 & Without vaccination, I am more likely to catch COVID-19 & & & .811 \\
\hline S8 & $\begin{array}{l}\text { COVID-19 is a serious disease for everybody with my working } \\
\text { conditions }\end{array}$ & & & .815 \\
\hline S9 & COVID-19 may have serious side effects for my health & & & .816 \\
\hline S10 & $\begin{array}{r}\text { Receiving a reliable vaccine effectively reduces chance of } \\
\text { catching COVID-19 or its side effects. }\end{array}$ & Perceived benefits & 0.79 & .811 \\
\hline S11 & $\begin{array}{r}\text { Receiving a reliable vaccine effectively help me being safe } \\
\text { when exposed to coronavirus in workplace }\end{array}$ & & & .814 \\
\hline S12 & $\begin{array}{r}\text { The adverse effects of catching COVID-19 are more severe } \\
\text { than the vaccine. }\end{array}$ & & & .816 \\
\hline S13 & $\begin{array}{r}\text { Although the COVID-19 vaccine is approved by WHO, but also } \\
\text { its safety has not been adequately investigated }\end{array}$ & Perceived barriers & 0.85 & .828 \\
\hline S14 & $\begin{array}{l}\text { There is currently little scientific evidence about vaccine } \\
\text { induced immunity for any type of the COVID-19 vaccine }\end{array}$ & & & .830 \\
\hline S15 & $\begin{array}{r}\text { I'm worried about the known side effects of the COVID-19 } \\
\text { vaccine, even approved vaccines }\end{array}$ & & & .826 \\
\hline S16 & $\begin{array}{r}\text { I'm worried about the unknown genetic changes caused by the } \\
\text { COVID-19 vaccine }\end{array}$ & & & .830 \\
\hline S17 & $\begin{array}{r}\text { I'm worried about the ineffectiveness of the COVID-19 vaccine, } \\
\text { even approved vaccines }\end{array}$ & & & .831 \\
\hline S18 & $\begin{array}{r}\text { I believe in my ability to decide on receiving the COVID-19 } \\
\text { vaccine }\end{array}$ & Self-efficacy & 0.45 & .827 \\
\hline S19 & $\begin{array}{r}\text { I believe in my ability to accept and deal with the side-effects } \\
\text { of the COVID-19 vaccination }\end{array}$ & & & .827 \\
\hline
\end{tabular}

\section{Figures}




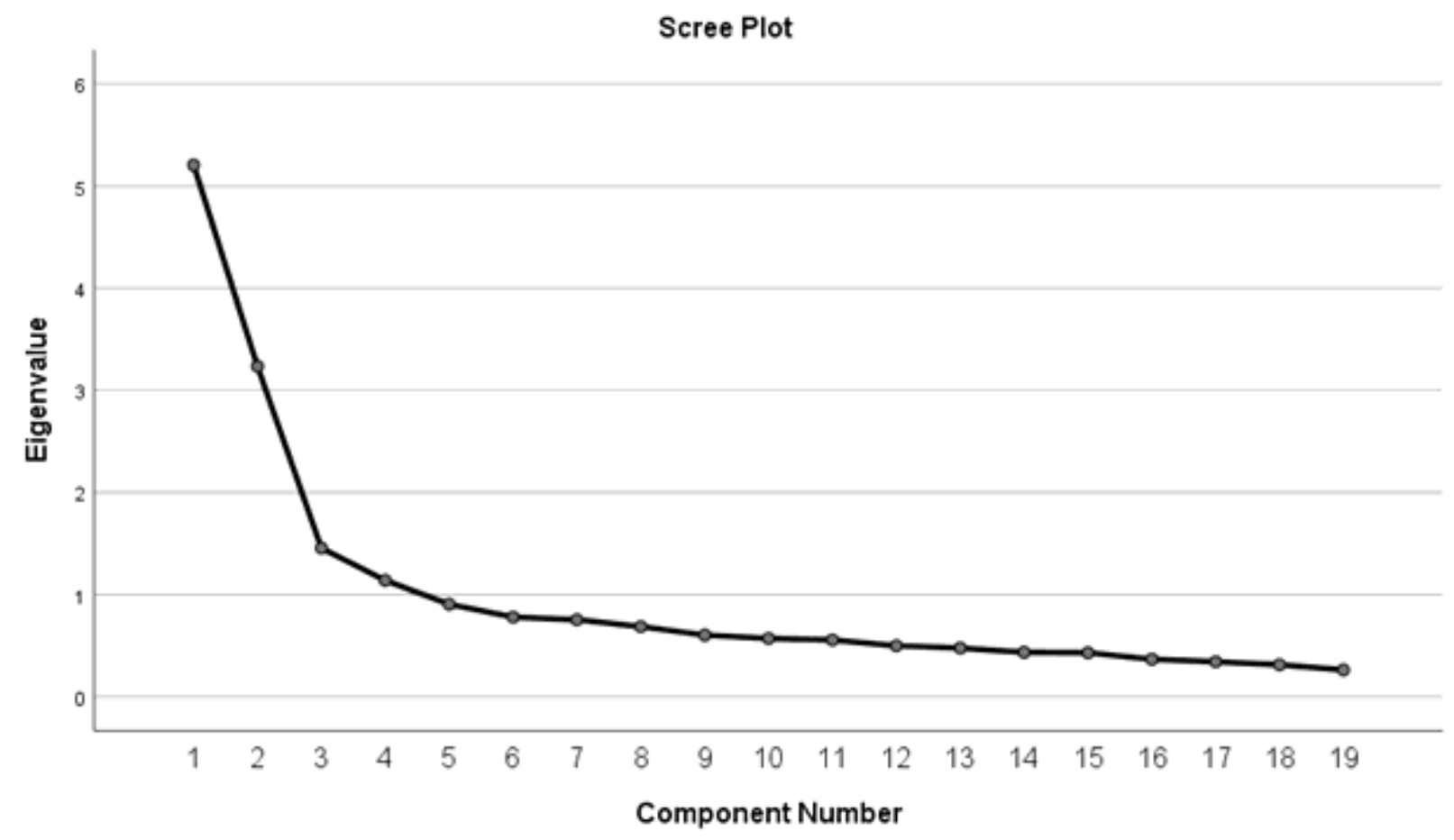

Figure 1

Gravel diagram of exploratory factor analysis of Intention to receive Covid-19 vaccine questionnaire based on health belief model 


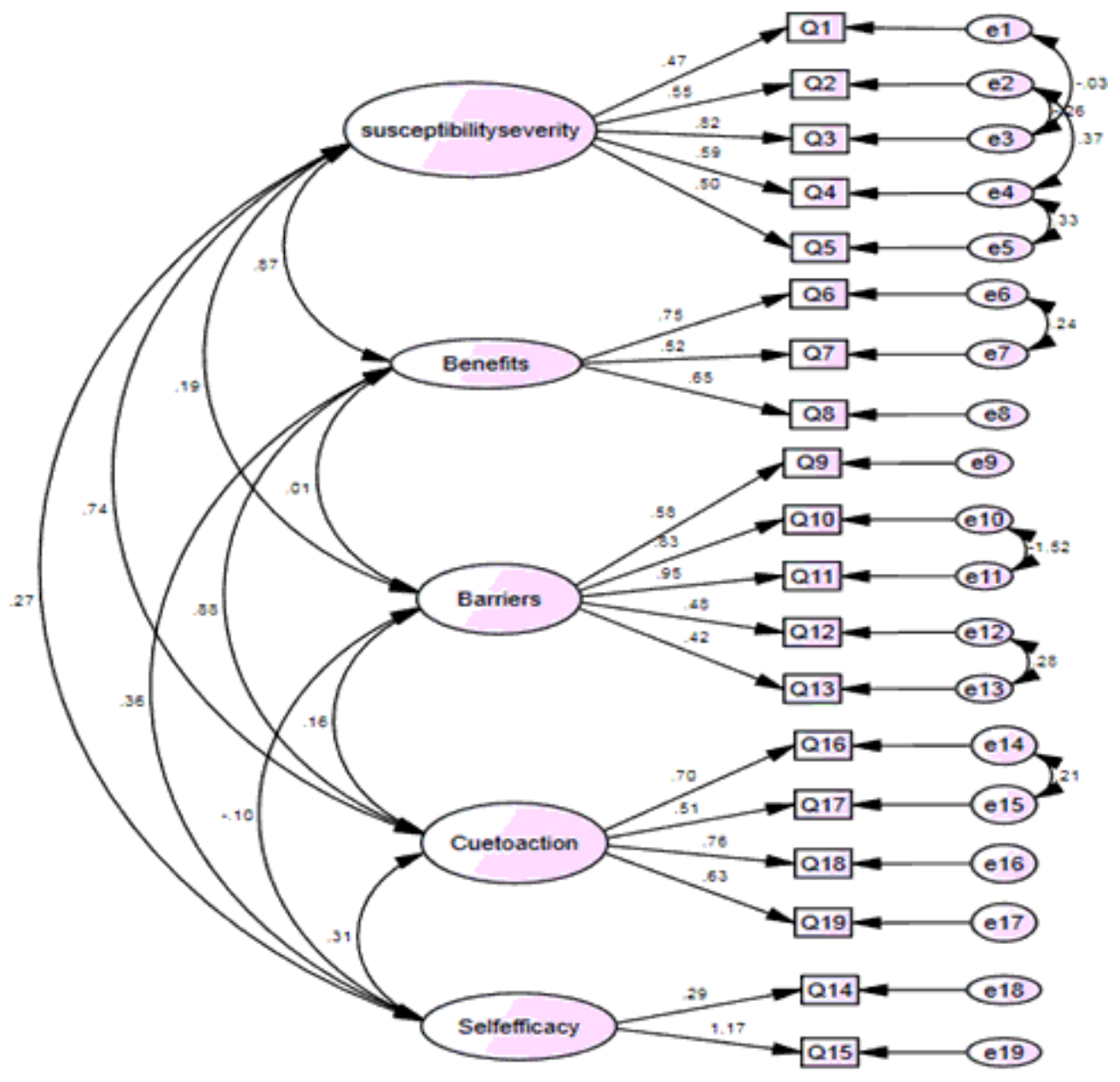

Figure 2

Confirmatory analysis and the final model of the intention to receive the vaccine using the health belief model 